\title{
DÜBLIN
}

Technological University Dublin

ARROW@TU Dublin

2016

\section{A coplanar vivaldi antenna with integrated filter for Ka-band}

\author{
Kansheng Yang \\ Technological University Dublin, kansheng.yang@tudublin.ie \\ Abraham Loutridis \\ Technological University Dublin \\ Xiulong Bao \\ Technological University Dublin, xiulong.bao@tudublin.ie
}

See next page for additional authors

Follow this and additional works at: https://arrow.tudublin.ie/ahfrccon

Part of the Electrical and Computer Engineering Commons

\section{Recommended Citation}

K. Yang, A. Loutridis, X. Bao, P. McEvoy and M. J. Ammann, "A coplanar vivaldi antenna with integrated filter for Ka-band," 2016 Loughborough Antennas \& Propagation Conference (LAPC), 2016, pp. 1-4, doi: 10.1109/LAPC.2016.7807545.

This Conference Paper is brought to you for free and open access by the Antenna \& High Frequency Research Centre at ARROW@TU Dublin. It has been accepted for inclusion in Conference Papers by an authorized administrator of ARROW@TU Dublin. For more information, please contact arrow.admin@tudublin.ie, aisling.coyne@tudublin.ie,gerard.connolly@tudublin.ie. 
Authors

Kansheng Yang, Abraham Loutridis, Xiulong Bao, Patrick McEvoy, and Max Ammann

This conference paper is available at ARROW@TU Dublin: https://arrow.tudublin.ie/ahfrccon/56 


\title{
A Coplanar Vivaldi Antenna with Integrated Filter for Ka-Band
}

\author{
Kansheng Yang, Abraham Loutridis, Xiulong Bao, Patrick McEvoy, Max J. Ammann \\ Antenna \& High Frequency Research Centre \\ Dublin Institute of Technology Dublin, Ireland \\ Email: kansheng.yang@mydit.ie
}

\begin{abstract}
A new design approach of a dual-stub coplanar Vivaldi antenna with integrated filter is presented. The dual-stub excites coupling between a parasitic elliptical element and tapered slots. The dimensions of the parasitic element are studied and optimized for wide beamwidth. The bandpass filter is used for subharmonic suppression and pattern shaping.
\end{abstract}

Keywords-Dual-stub Vavildi antenna, Bandpass filter(BPF), parasitic antenna, filter antenna

\section{INTRODUCTION}

The Vivaldi antenna was firstly proposed by Gibson in 1979 [1]. The traveling wave antenna couples along the inner edge of the flared structure and radiates in endfire direction. It was widely used for beam scanning in radio astronomy [2] and phased arrays [3]. For a single Vivaldi element, research has mainly focused on wideband applications [4] and methods to improve the directivity of the radiation pattern.

In [5], an elliptical microstrip patch was added as a parasitic element to an Antipodal Vivaldi Antenna (AVA). It was reported to improve the directivity and gain in K-band. A dualstub double-slot structure was studied in [6]. The double-slot improved the directivity in Ku-band. Filter integrated antennas were studied in the millimeter-wave bands [7] and shown to be useful for sub-harmonic suppression. However, the multilayer structure for the filter can be simplified.

Although this paper follows a similar design methodology found in [5]-[7], a new approach to a dual-stub coplanar Vivaldi slot antenna with a parasitic element at $28 \mathrm{GHz}$ is presented. Key parameters are studied to adjust the frequency response and radiation characteristics. The presented structure with filter is low-profile and simple to fabricate.

\section{ANTENNA DESIGN}

\section{A. Antenna configuration}

The coplanar Vivaldi antenna is prototyped on Rogers RT/duroid 5870 substrate $\left(\varepsilon_{r}=2.33\right.$ and $\left.\tan \delta=0.0012\right)$ with dimensions $44.5 \times 32 \times 0.79 \mathrm{~mm}^{3}$. The antenna geometry is shown in Fig. 1. The antenna consists of a bandpass filter on the top side connected to the feed of a K-type $(2.92 \mathrm{~mm})$ connector.

This publication has emanated from research conducted with the financial support of Science Foundation Ireland (SFI) and is co-funded under the European Regional Development Fund under Grant Number 13/RC/2077.
The two stubs provide improved coupling to the tapered slots with the same amplitude and unequal phase.

The tapered slot side of the board is mirrored in the $\mathrm{x}$-axis. The exponential profile curve used in this design is:

$$
C(x)= \pm \mathrm{a} \times e^{\mathrm{p} x}
$$

where $\mathrm{a}=0.4$ and $\mathrm{p}=0.16$.

An elliptical parasitic element is positioned between the edge of the board and the slot aperture. The dual-stub structure couples to the parasitic element and the tapered slot to improve the radiating gain and increases the beamwidth.

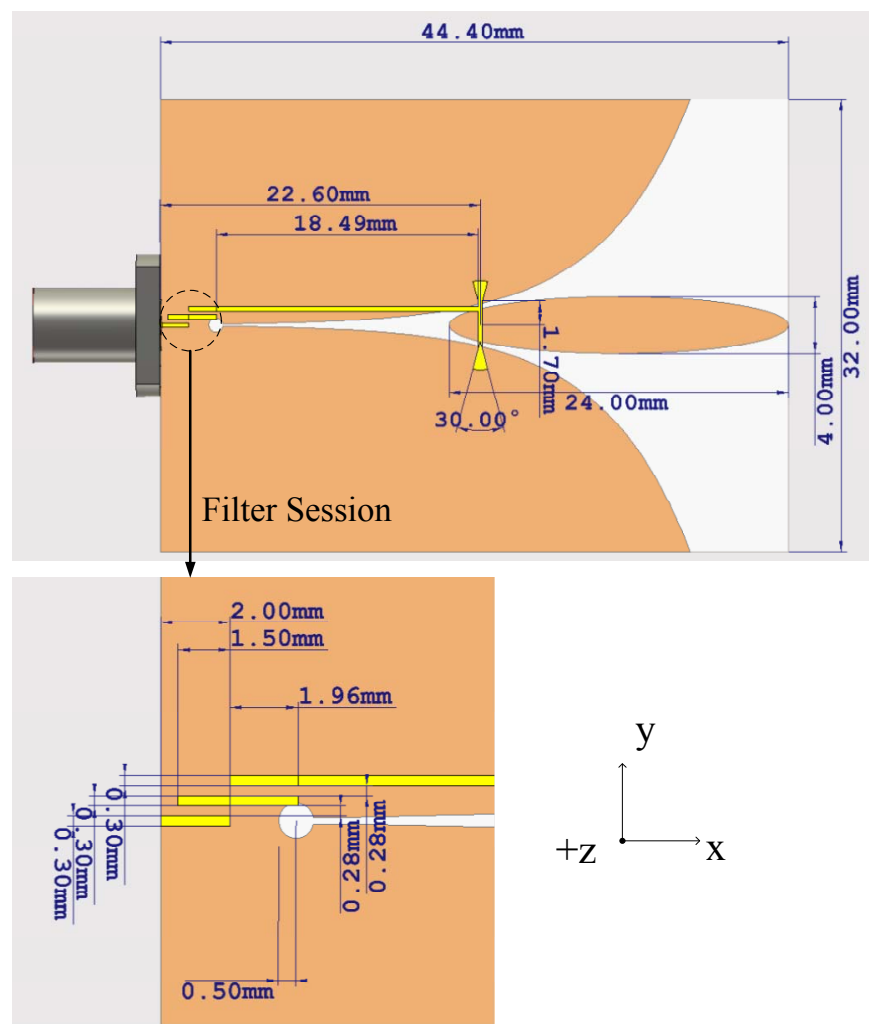

Fig. 1. Antenna geometry with dimensions. 


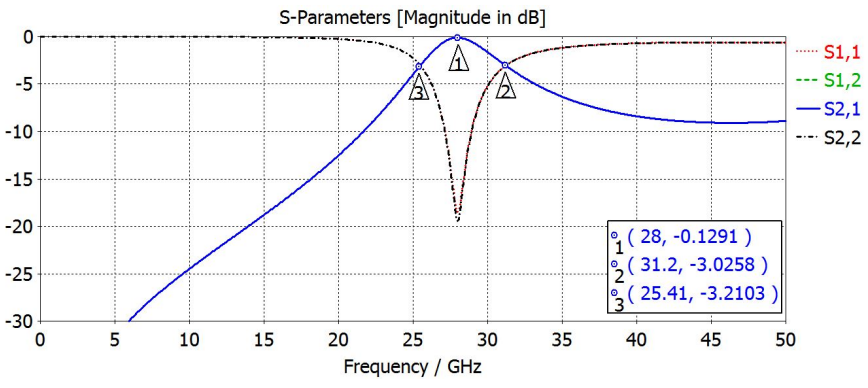

Fig. 2. Simulated response of the two-port filter.

\section{B. Bandpass filter session}

With a filter section added at the source end, the connector position is brought back to the edge of the board, thus minimizing squint due to the connector. The two-stage coupled filter has a microstrip width of $0.3 \mathrm{~mm}$ with a gap of $0.28 \mathrm{~mm}$. The simulated response of the two-port filter is shown in Fig. 2. This low-loss bandpass filter is designed at the centre frequency of $28 \mathrm{GHz}$ with a $3-\mathrm{dB}$ bandwidth from $25.41 \mathrm{GHz}$ to $31.2 \mathrm{GHz}$. The simulated $\mathrm{S}_{11}$ with and without the filter is shown in Fig. 3 . The filter improves the matching in the desired band and suppresses the sub-harmonics significantly.

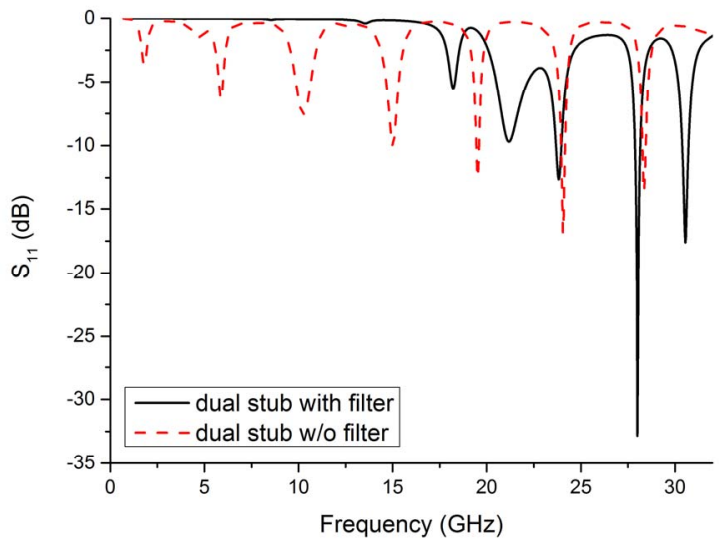

Fig. 3. Sumulated $S_{11}$ with and without the filter section.

\section{Antenna Performance StUdy}

\section{A. Optimization of exponential profile curves}

The parameters of the exponential curve $a$ and $p$ have a significant impact on the frequency response. As shown in Fig. 4, both $a$ and $p$ control the flare level, thus controlling the frequency. In this design, $a=0.4$ and $p=0.16$ are chosen.
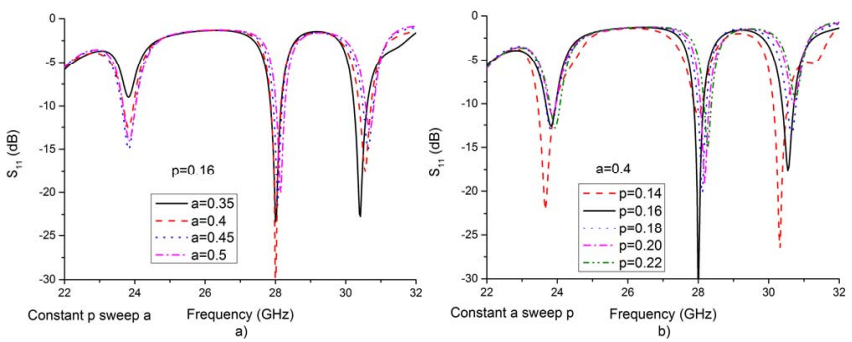

Fig. 4. Frequency sensitivity to the variation of $a$ and $p$.

\section{B. Microstrip ellipse geometry}

The elliptical parasitic element dimensions are also optimized. As similar to [5], the conclusion is that the position of the parasitic element should be located close to the throat of the flare to improve the coupling. The ratio of the shorter arm to long arm has a minor effect on the realized gain. However, the longer arm $(L a)$ of the ellipse has the most impact on the antenna gain. As shown in Fig. 5, when $L a=12 \mathrm{~mm}$, it has the highest radiation gain and minimum side lobes.

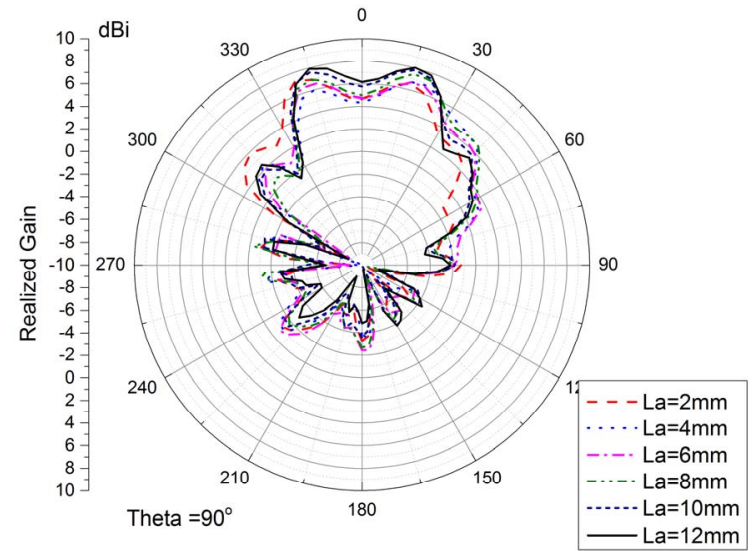

Fig. 5. Realized gain sensitivity to variation of $L a$ for $\theta=90^{\circ}$ at $28 \mathrm{GHz}$.

\section{Parametric study on ground plane width}

The ground plane width also changes the radiation pattern. A parametric study carried out for $\theta=90^{\circ}$ in Fig. 6. The narrow ground width of $20 \mathrm{~mm}$ provides the highest gain of $9.8 \mathrm{dBi}$ with an HPBW of $30^{\circ}$. In this design, $32 \mathrm{~mm}$ is chosen for the final design. It provides the widest HPBW of $51^{\circ}$ with a maximum gain of $8.2 \mathrm{dBi}$. It is noted that the side lobe radiation is not mirrored due to the difference of the unequal stub path phase.

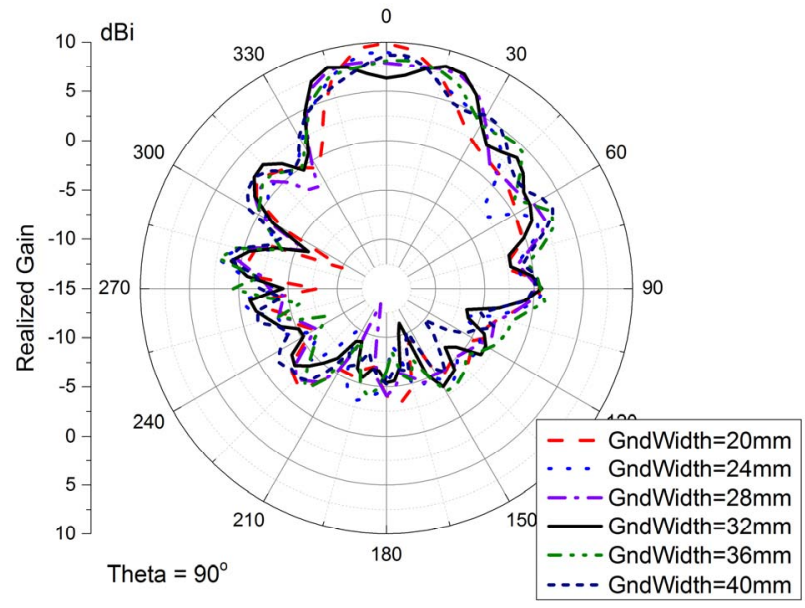

Fig. 6. Radiation pattern sensitivity to variation of ground plane width for $\theta=90^{\circ}$ at $28 \mathrm{GHz}$.

D. Comparison of the single and dual-stub design

A single-stub Vivaldi antenna is designed in Fig. 7 with the same configurations for comparison on the antenna performance. Simulations are carried out with and without the parasitic element for both dual and single-stub situations, as shown in Figs. 8 and 9. It should be noted that the feed positions 


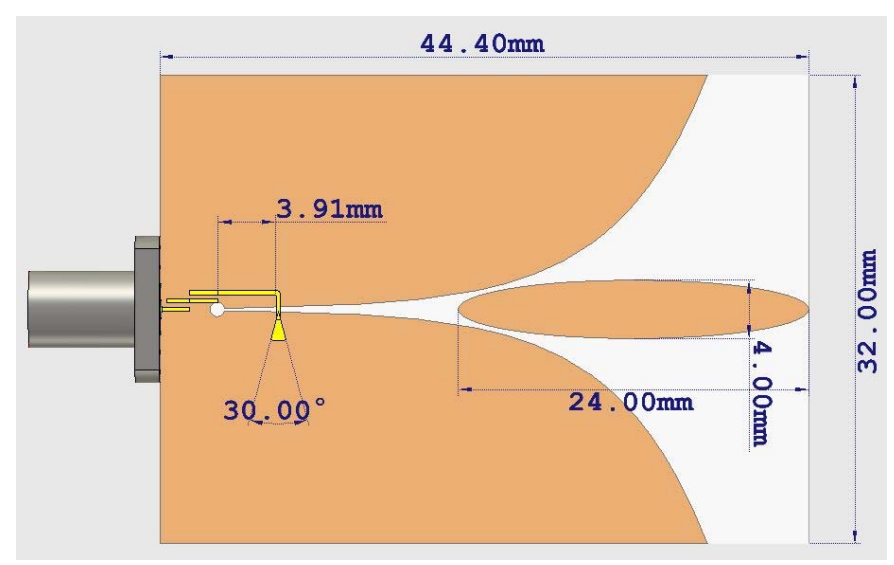

Fig. 7. Single-stub coplanar Vivaldi antenna design.

for both single and dual-stub cases are optimized before removing the parasitic component.

Fig. 8 demonstrates that the parasitic element helps to eliminate undesired frequency responses and Fig. 9 shows that the parasitic element improves the endfire radiation. As seen in Fig. 9, the realized gain has increased by $3 \mathrm{~dB}$ compared to the single-stub feed methodology.

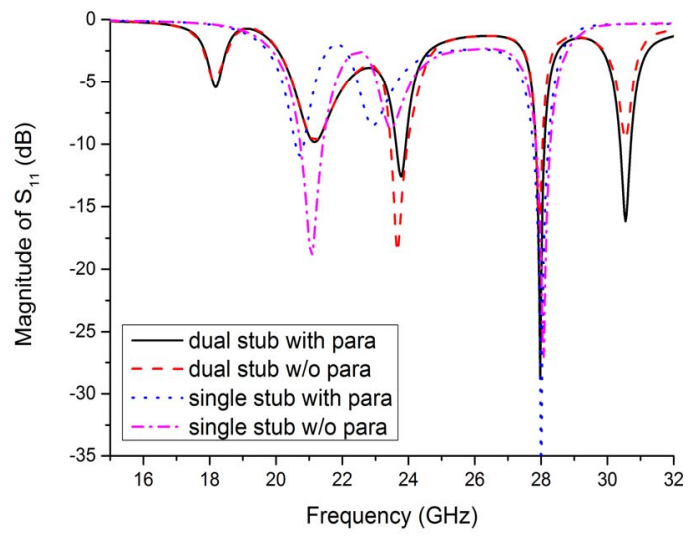

Fig. 8. $\mathrm{S}_{11}$ comparison of the single and dual stub design.

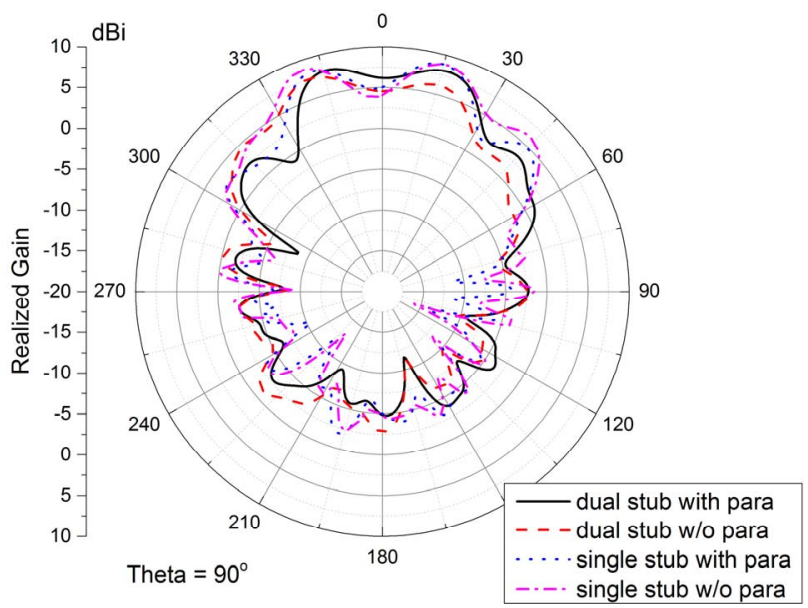

Fig. 9. Radiation pattern comparison of the single and dual stub design for $\theta=90^{\circ}$ at $28 \mathrm{GHz}$ with and without parastic ellpise.

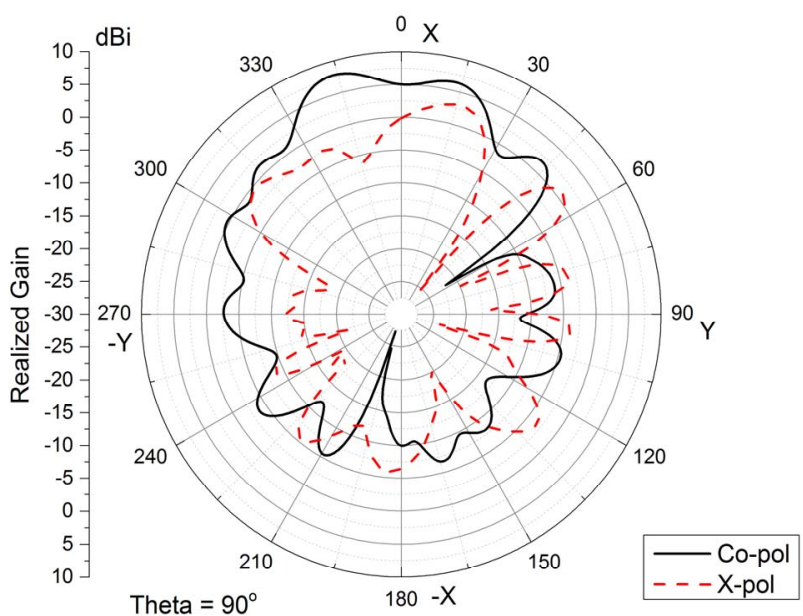

a)

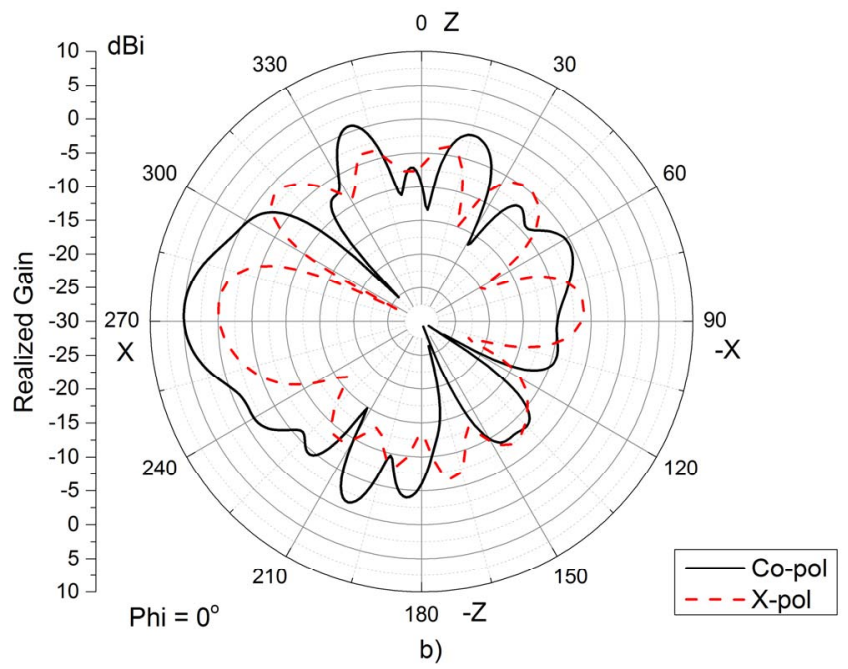

Fig. 10. Simulated radiation pattern at $28 \mathrm{GHz}$. a) $\theta=90^{\circ}$ b) $\varphi=0^{\circ}$

\section{E. Final result presentation}

The antenna radiates at $28 \mathrm{GHz}$ with a $10 \mathrm{~dB}$ impedance bandwidth of $262 \mathrm{MHz}$. The simulated total efficiency is $81.2 \%$. The simulated radiation pattern is shown in Fig. 10. The maximum realized gain is $8.2 \mathrm{dBi}$. The HPBW is reported to be $52^{\circ}$ at $\theta=90^{\circ}$ with more than $120^{\circ}$ endfire radiation gain greater than $0 \mathrm{dBi}$. At $\varphi=0^{\circ}$ the $\mathrm{HPBW}$ is $31.4^{\circ}$ with $60^{\circ}$ radiation gain greater than $0 \mathrm{dBi}$.

\section{CONCLUSION}

A new dual-stub feed Vivaldi antenna design with an elliptical parasitic element is proposed. The reported antenna provides greater coupling to the tapered slots achieving higher gain at $8.2 \mathrm{dBi}$ and the elliptical element increases the beamwidth to $51^{\circ}$. The bandpass filter section is added at the source end for harmonic suppression. This coplanar Vivaldi antenna is suitable for $5 \mathrm{G}$ communications at $28 \mathrm{GHz}$ and could be further studied for mobile embedded system.

\section{REFERENCES}

[1] P. J. Gibson, 'The Vivaldi Aerial', in Microwave Conference, 1979. 9th European, 1979, pp. 101-105. 
[2] E. W. Reid, L. Ortiz-Balbuena, A. Ghadiri, and K. Moez, 'A 324-Element Vivaldi Antenna Array for Radio Astronomy Instrumentation', IEEE Trans. Instrum. Meas., vol. 61, no. 1, pp. 241-250, Jan. 2012.

[3] J. Shin and D. H. Schaubert, 'A parameter study of stripline-fed Vivaldi notch-antenna arrays', IEEE Trans. Antennas Propag., vol. 47, no. 5, pp. 879-886, May 1999.

[4] S. Wang, X. D. Chen, and C. G. Parini, 'Analysis of Ultra Wideband Antipodal Vivaldi Antenna Design', in 2007 Loughborough Antennas and Propagation Conference, 2007, pp. 129-132.

[5] I. T. Nassar and T. M. Weller, 'A Novel Method for Improving Antipodal Vivaldi Antenna Performance’, IEEE Trans. Antennas Propag., vol. 63, no. 7, pp. 3321-3324, Jul. 2015
[6] Y. W. Wang, G. M. Wang, and B. F. Zong, 'Directivity Improvement of Vivaldi Antenna Using Double-Slot Structure', IEEE Antennas Wirel. Propag. Lett., vol. 12, pp. 1380-1383, 2013.

[7] A. Abbaspour-Tamijani, K. Sarabandi, and G. M. Rebeiz, 'Antennafilter-antenna arrays as a class of bandpass frequency-selective surfaces', IEEE Trans. Microw. Theory Tech., vol. 52, no. 8, pp. 1781-1789, Aug. 2004. 